\title{
Modernization of Construction Educational Programs Taking Into Account Building Information Modeling Technologies
}

\author{
Elena Valentinovna Ignatova \\ Department of Information Systems, Technology and Automation in Construction \\ Moscow State University of Civil Engineering (MGSU) National Research University \\ Moscow, Russia \\ ignatova@mgsu.ru
}

\begin{abstract}
The global processes and their impact on the construction industry and construction education are discussed. The goals and objectives of the digital transformation of construction are discussed. It is noted that building information modeling is one of the ways of digitalization and modernization of construction. Modernization of construction educational programs is considered. The main requirements for the content of educational programs at the present stage of development of digital technologies in construction are analyzed. When creating a professional educational program, it is necessary to take into account the requirements of employers and professional standards. Currently, there are no professional standards related to building information modeling. The experience of competence formation in the field of building information modeling is considered. It is proposed to take into account the principles of the international initiative CDIO when developing the educational program. The scheme of the main factors influencing the formation of the educational program is presented. Digital competences that are necessary for building information modeling are formulated. Definitions of competences for the project of professional standard and for the educational standard in the field of construction are offered.
\end{abstract}

Keywords - educational programs; globalization; digitalization; building information modeling

\section{INTRODUCTION}

Educational programs of secondary professional and higher education are formed taking into account the requirements of Federal state educational standards, professional standards, exemplary educational programs and taking into account the current level of development of science and technology. To develop the content of educational programs different approaches and methods are used, which depend on the selected educational technologies and resources of the educational organization. Federal state educational standards contain definitions of universal and general professional competences of graduates, and also can contain the list of professional competences. The list of obligatory and recommended professional competences is specified in the approximate educational program. An educational organization can formulate its own professional competencies based on the labor functions of the selected professional standards. The result of mastering the educational program is the formation of a complete set of certain students' competencies [1]. Each discipline, module, course, practice of the educational program should contribute to the formation of these competencies.

Russia has approved a program of digitalization of the economy. The construction industry responds to the need for digital transformation by introducing building information modeling technologies (BIM technologies) [2,3]

The technology of building information modeling appeared as a consequence of the development of methods and tools for creating computer three-dimensional geometric models of complex shapes. The technology is based on digital parametric object-oriented modeling of the building and its constituent elements. A characteristic feature of the technology is not only modeling the geometric characteristics of the building (shape, size, position in space), but also the representation of non-geometric information (building materials, manufacturer, classifier codes, etc.). The digital information model represents geometrical, physical, functional and other characteristics of object (or its separate parts) in the form of set of information saturated elements. Digital information model of the building allows to automatically obtain accurate drawing documentation and specifications of model elements. It is possible to make consistent changes to the model and all related documents. At the present stage of development, information modeling technology is applied not only to models of buildings, but also to models of structures, as well as to models of terrain. The general information model of the construction object can consist of a set of information models related to various tasks of specialists. It is important to note that the information model should be created and updated to accompany the entire life cycle of the construction object. Building information modeling changes the organization of work of specialists. All participants of the information modeling process should work together and communicate on the basis of a single information model of the construction object. Currently problems that can be solved with the use of building information modeling technologies at the stages of research, design, construction, operation, liquidation of a construction object are discussed $[4,5,6,7,8]$. The global issue of implementation of information modeling technologies in the construction sector was considered at the world economic forum (WEF) in February 2018. The main steps to the modernization of the construction industry were identified, 
including the development of employees to participate in the information modeling processes.

"BIM skills are core capabilities in a digitalized construction industry, and as a result, they cannot be outsourced to third parties. Organizations have three options for increasing their BIM talent pool: hiring new talent with the required skills, upskilling the existing workforce, and simplifying BIM technology and processes to reduce required skills. Education must be reformed to provide prospective employees with necessary BIM skills as well as the interdisciplinary skills required for BIM collaboration. Courses should teach students tangible, applicable BIM knowledge through practical, hands-on training. Universities, vocational and professional training providers should integrate BIM into general design and engineering classes rather than offer courses as electives or add-ons. Upskilling the existing workforce can be done on the job or in the classroom. In either case, IU companies and industry associations should work with professional providers and academia to develop upskilling courses. Companies should institute a broad set of internal upskilling programmes." [9].

In Russia, it is stated that a life cycle management system of the construction object should be formed on the basis of building information modeling technologies [10]. Intensive work is carried out to identify and formulate the necessary digital competencies of construction workers. Changes in the relevant professional standards are being prepared. New academic disciplines, modules, courses and new educational programs in the field of Construction for undergraduate and graduate levels are being formed.

The aim of the study is to determine the significant factors and ways of modernization of educational programs of the construction direction on the basis of information modeling technologies.

\section{MethodS AND MATERIALS}

The study uses a systematic approach to determine the factors affecting the formation of disciplines content associated with the use of building information modeling technologies. The methods of analysis and synthesis are used to determine the basic knowledge and practical skills in the field of building information modeling.

\section{A. Digital transformation of construction}

As part of the implementation of the digital economy program, each branch of the economy forms its own program of digitalization and road map of transformation. Currently, a program of digital transformation of the construction industry is being formed. The goals and main tasks of transformation are defined [11].

\section{The goals of digital transformation of construction are:}

- ensuring the collection and analysis of information which is necessary for the development of policy in the field of construction and housing and communal services at all stages of the life cycle of the construction object;
- reducing the cost of obtaining information and documentation required for urban planning.

The main tasks of digital transformation of construction are:

- conversion of all procedures of the urban planning process into electronic form;

- implementation of building information modeling technologies;

- development of information systems for storage of documentation, building information models, statistical information and implementation of electronic procedures;

- development of digital competencies in the construction industry.

\section{B. Digital competencies}

The problem of preparing workers for the digital economy is global. International scientific and methodological centers and their satellites are organized to conduct research in the field of digital economy training. Digital competencies that need to be formed in the institutions of general secondary education, secondary special education and higher education are discussed. Great hopes for the formation of digital competencies are placed on educational programs of additional education of children and adults, as well as on educational programs of additional professional education. For specialists in the field of management, including public administration, an educational program CDO (Chief Data Officer) was developed. The purpose of the program is to develop the competence of data management. CDTO (Chief Data Transformation Officer) programs are developed for managers responsible for the implementation of digital development projects.

In Russia, there are currently two parallel processes to determine the necessary digital competencies: in the professional community and in the educational community. The professional community, national associations of specialists and committees for professional qualifications discuss the necessary set of labor functions, knowledge and skills that should be included in the professional standards. The educational community, universities, educational and methodical associations discuss the necessary universal, general professional and professional digital competencies that should be included in the Federal state educational standards, exemplary educational programs, basic educational programs of secondary professional and higher education.

A model of digital competencies has been developed, including basic and advanced levels of digital competencies. The basic level assumes the possession of key competencies of the digital economy at the level which is not lower than international one, which is developed taking into account international studies PIAAC (Problem solving in technology rich environments). Key competencies should be included in the digital core of Federal state educational standards. Advanced level involves professional knowledge of competencies in the field of information technology and 
mathematics to solve industry problems in the framework of the development of the digital economy program.

Within the framework of the action plan "Staff and education" of the program "Digital economy of the Russian Federation" the Fund of development of educational technologies is organized. Its main tasks are:

- financing breakthrough educational projects aimed at training the staff for new markets and technologies, as well as meeting the staffing needs of the digital economy of the Russian Federation;

- creation of a database of promising educational technologies using the best world practices in order to transform the education system.

\section{Professional standards}

In Russia professional standards determine the qualification levels and labor functions of employees, as well as the knowledge and skills necessary to perform them. Professional standards provide guidance in the formation of educational programs of secondary professional, higher and additional education. Professional standards are used in the independent assessment of specialist qualifications. Currently, professional standards in the construction industry do not contain requirements for digital competencies of specialists. The first professional standard related to BIM technologies, "Specialist in digital design of nuclear energy facilities", was approved in 2019. The draft of a new professional standard "Specialist in information modeling in the field of construction" is discussed [9].

\section{Basic competencies for working with building information modeling technologies}

Building information modeling technologies should accompany the entire life cycle of the construction object from the idea of its creation to liquidation, so all specialists of the construction industry should understand the basic principles of building information modeling. The result of BIM is information, documents, data about the object and its digital information models.

There are approaches to the allocation of basic competencies in building information modeling technologies $[12,13,14]$. The international organization BuildingSmart based its certification programs on the knowledge and understanding of the OpenBIM concept [15]. The English manual "Practical implementation of BIM for the UK Architectural, Engineering and Construction (AEC) industry" classifies the roles and functions of BIM specialists, establishes the principles of teamwork of specialists and interoperability of software [16]. In Germany, the standard of qualifications in the field of BIM was passed. It defines the basic knowledge on which educational programs for different specialists should be based. Specialists should know the basic terminology, as well as the factors of development of BIM technologies: people, processes, information, technology, environment and their interaction [17]. In Sweden, a survey of construction organizations identified the most significant factors for successful work with BIM-technologies: the presence of higher engineering education, experience in computer 3D modeling, design experience, understanding of construction technologies, project management experience [18]. In Russia, there are examples of the development and implementation of educational programs of higher education, taking into account the use of competence-based approach and information modeling technologies in construction [19]. The experience of training has shown that it is not enough to introduce the use of BIM-technologies into practical classes of construction disciplines or to add the discipline about information modeling technologies to the educational program of the construction direction. A comprehensive approach to the modernization of the educational program is needed [20, 21, 22].

\section{E. International initiative $C D I O$}

The most well-known methodology for reforming engineering education is the international initiative CDIO [23]. The initiative is based on the "Conceive - Design implementation - Operate" algorithm. The concept of CDIO provides that the creation and development of objects, processes and systems throughout their life cycle should become the general context of engineering education.

The aim of the initiative is to bring the content and effectiveness of engineering educational programs in line with the level of development of modern technologies and expectations of employers. It should be noted that the gap between the results of education and the requirements of economic sectors to the competencies of graduates of educational institutions is a global problem, so it requires a universal solution. The CDIO initiative was proposed as a result of the activities of the international University community. Twelve CDIO standards were adopted to reform undergraduate education programs. The standards define

- the concept of engineering education;

- $\quad$ principles of curriculum formation;

- requirements for practice-oriented educational environment;

- requirements for teaching methods and teachers qualifications;

- requirements for methods of evaluation of learning outcomes and the educational program as a whole.

The use of CDIO principles makes it possible to develop a comprehensive approach to training graduates in technical areas to conduct engineering activities at all stages of the life cycle of technical and technological products [24]. CDIO Syllabus identifies four groups of education outcomes. There are:

- Technical Knowledge and Reasoning;

- Personal and Professional skills and attributes;

- Interpersonal skills: Teamwork and Communication;

- Conceiving, Designing, Implementing and Operating systems in the enterprise and societal context. 
Currently, the CDIO initiative has been joined by more than 120 educational organizations around the world, from seven regions of the world, including about 30 Russian universities. Over the twenty years, the CDIO initiative has been developed for graduate and postgraduate education programs and even for additional professional education.

The analysis of the principles of information modeling of construction objects and CDIO principles shows the consistency of their goals and the possibility of joint application in the development of educational programs [25]. Information modeling technology includes the following goals of building life cycle.

- to conceive, i.e. to define needs in construction, development of the concept of objects and the investment project;

- to design, including conceptual design, detailed design, analysis and calculations, preparation and approval of documentation;

- to build, i.e. to conduct the preparation of construction, construction, installation of equipment;

- to operate, combining the operation, renovation and disposal of the facility.

\section{RESULTS}

As a result of the study a system of significant factors for the formation of educational programs in the field of construction was defined (Fig. 1). The digital transformation of the construction industry includes changes in construction processes, the use of new technologies and the formation of digital competencies of specialists. Building information modeling technology is the basis for life cycle management of construction objects.

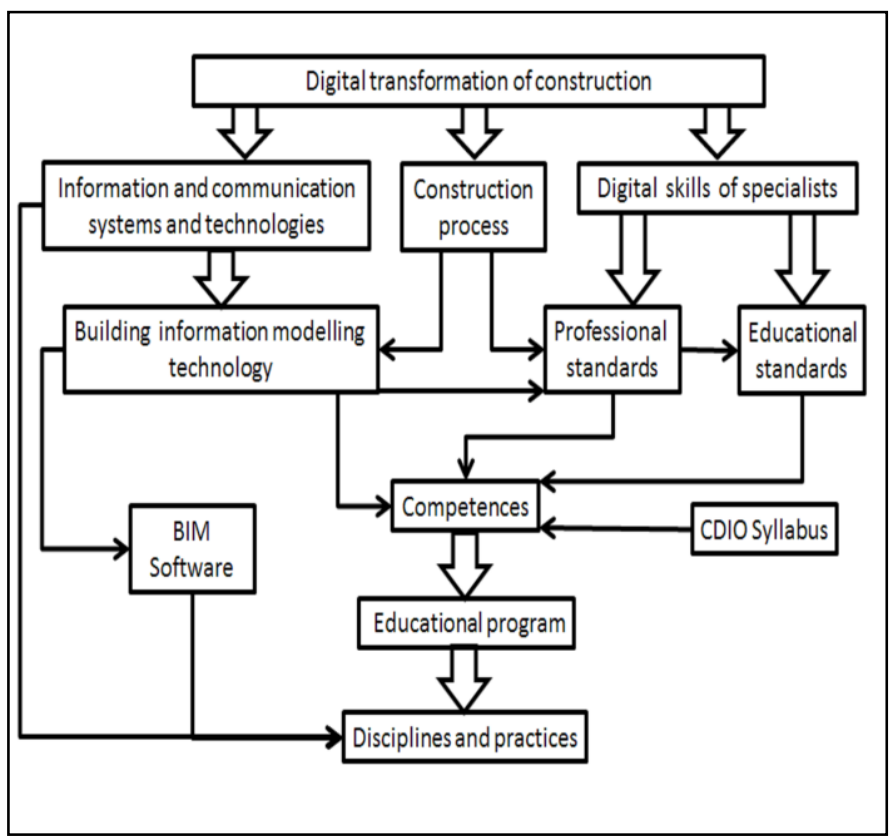

Fig. 1. Significant factors for the development of educational programs.
The general professional competences that are necessary to effective use of BIM technologies are defined. These include:

- ability to create a 3D parametric object-oriented digital information model of the construction object with the necessary level of detail of geometry and information;

- ability to retrieve, process and transmit information model data;

- ability to solve profile problems of a certain stage of the life cycle of the construction object and to form technical documentation with the use of information and communication technologies, including BIM technologies;

- ability to manage the processes of information modeling of the construction object.

On the basis of the listed competences, the draft of the professional standard "Specialist in information modeling in the field of construction" has been developed by the author of the paper. It is offered that the main labor functions are:

- technical support of information modeling process;

- creation of the information model of the construction object and its use for solving discipline tasks;

- organization of the development and the use of building information modeling, including collective work with information;

- management of the information modeling processes in the implementation of investment and construction projects;

- management of the implementation and the development of BIM technologies in the organization.

The draft professional standard describes the knowledge and skills required to work with BIM technologies.

The basic knowledge and skills that are necessary for all specialists to work with information modeling technologies are allocated to form the content of educational programs. The basic knowledge contains the following topics:

- principles of BIM (three-dimensional, parametric, object-oriented modeling; collaboration in a shared data environment; software integration and data transfer formats; support the entire lifecycle of construction object);

- participants and tasks of BIM at different stages of building the life cycle;

- experience of use and prospects of development of BIM technologies;

- BIM process management;

- standardization in the field of BIM;

- implementation of BIM technologies in the activities of organizations. 
Basic knowledge and skills should be the basis for the development of the content of the discipline "Fundamentals of building information modeling" or the section of disciplines "Construction Informatics", "Information technologies in construction", "Information modeling Technologies".

Practical studies of different constructional disciplines should be carried out with BIM software. The skills of collaboration should be gained on the basis of multidiscipline projects.

\section{CONCLUSIONS}

The paper analyzes the development trends of the construction industry, construction education and digital competencies of specialists.

Significant factors for modernization of educational programs of construction have been defined taking into account BIM technologies: the development of digital economy, information and communication systems and technologies, building information modeling technologies, the development of the construction process, the application of international educational standards.

One of the challenges of digital economy is the permanent necessity to modernize professional educational programs to satisfy the current level of technologies of corresponding field of economy. In construction industry, the development of technologies is connected with implementation of building information modeling.

The basic knowledge and skills necessary for information modeling of construction objects has been defined.

These skills and knowledge formed the base for the draft of professional standard "Specialist in the field of information modeling in construction", which was proposed by the author of the paper. These competences can be also the base of educational programs.

In the future, the BIM content of disciplines related to the solution of specialized tasks at different stages of the life cycle of the construction object will be developed.

\section{Acknowledgment}

The work was carried out within the grant of the President of the Russian Federation for state support of leading scientific schools of the Russian Federation, No. NSH-3492.2018.8.

\section{References}

[1] Federal Law on education in Russian Federation No 273, 29.12.2012.

[2] V. Kupriyanovsky, S. Sinyagov and A. Dobrynin, "BIM - Digital Economy. How to achieve the success? A practical approach to the theoretical concept. Part 1: Approaches and the main advantages of BIM," International Journal of Open Information Technologies, Vol. 4 , 3, 2016.

[3] A. Dobrynin, K. Chernykh, V. Kupriyanovsky, P. Kupriyanovsky and S. Sinyagov, "The Digital Economy - the various ways to the effective use of technology (BIM, PLM, CAD, IOT, Smart City, BIG DATA, and others)." International Journal of Open Information Technologies, Vol. 4, 1, 2016.
[4] E. Ignatova, S. Zotkin and I. Zotkina, "The extraction and processing of BIM data,” IOP Conf. Series: Materials Science and Engineering, Vol. 365.

[5] H-J. Bargstädt, A.R. Nasir and E.V. Ignatova, "Can BIM support better working conditions for low-skilled labor?", Proceedings 14th International Conference on Construction Applications of Virtual Reality in Construction, Sharjah UAE, 2014, pp. 44-51.

[6] Saeed Rokooei, "Building Information Modeling in Project Management: Necessities, Challenges and Outcomes - Social and Behavioral Sciences,“ Vol. 210, 2, December 2015, pp.87-95.

[7] C. Peng, "Calculation of a building's life cycle carbon emissions based on Ecotect and building information modeling," Journal of Cleaner Production, Vol. 112, Part 1, 20 January 2016, pp. 453-465.

[8] M. Sakin, Y.C. Kiroglu, "3D Printing of Buildings: Construction of the Sustainable Houses of the Future by BIM," Energy Procedia, Vol. 134, October 2017, pp. 702-711.

[9] Shaping the future of construction. An action plan to accelerate Building Information Modeling (BIM) Adoption. In collaboration with The Boston Consulting Group, World Economic Forum, Geneva, Switzerland, February 2018.

[10] V.V Putin "Instructions for the government of the Russian Federation 19.07.2018," Moscow: Kremlin, 2018.

[11] A.I. Vishnivetskaya, T.Kh. Ablyazov, "Features of the concept of digital transformation of investment and construction sector," J. Vestnik Altayskoy akademii ekonomiki i prava, Vol.3-2, 2019, pp 28-37.

[12] R.A. Rahman, S. Alsafouri, P. Tang, S.K. Ayer, "Comparing Building Information Modeling Skills of Project Managers and BIM Managers Based on Social Media Analysis,'Procedia Engineering, Vol. 145, 2016 , pp. 812-819.

[13] L.M. Khodeir and A.A. Nessim, "Changing skills for architecture students employability: Analysis of job market versus architectureeducation in Egypt," Ain Shams Engineering Journal.

[14] M. Uhm, G. Lee, B. Jeon, "An analysis of BIM jobs and competencies based on the use of terms in the industry Automation in Construction", Vol. 81, September 2017, pp. 67-98.

[15] Training curriculum 01 - Basic, BuildingSMART, Norway, 2017.

[16] AEC (UK) BIM Technology Protocol, UK, 2015.

[17] VDI/BS-MT 2552 Blatt 8.1:2019-01 "Building information modeling Qualifications - Fundamental knowledge," Germany, 2019

[18] P.M. Bosch-Sijtsema, P. Gluch and A.A. Seze, "Professional development of the BIM actor role", J. Automation in Construction, Vol. 97, 2019, pp. 44-51.

[19] Yu.A. Lezhnina, T.V. Khomenko, "Development of module "Building Information modeling" on the basis of competence approach," J. Izvestia Kazanskouo gosularstvennogo arhitekturno-stroitelnogo universiteta, Vol. 2 (40), 2017, pp. 322-330.

[20] M.M. Joannides, R.A. Issa and S. Olbina, "Implementation of BIM into architecture and construction educational curriculum," J. of Building Information Modeling, 2011, pp 29-31.

[21] Badiru Yunusa Yusuf, Kherun Nita Ali, Muhammad Rashid Embi, "Building Information Modeling as a Process of Systemic Changes for Collaborative Education in Higher Institution," Procedia - Social and Behavioral Sciences, Vol. 219, 31 May 2016, pp. 820-827.

[22] S. Soliman, D. Taha, Zeyad El Sayad, "Architectural education in the digital age: Computer applications: Between academia and practice", Alexandria Engineering Journal, Vol. 58, Issue 2, June 2019, pp. 809818

[23] E.F. Crawley, "The CDIO Syllabus. A Statement of Goals for Undergraduate Engineering", Education Department of Aeronautics and Astronautics Massachusetts Institute of Technology, 2001

[24] H. Abdirad, C.S. Dossick, "BIM curriculum design in architecture, engineering, and construction education: a systematic review," J. of Information Technology in Construction (ITcon), Vol. 21, 2016, pp. 250-271

[25] A. Krogsboll, C.S. Jørgen, E. Christensen, T. Beier, L.P. Goltermann, H. Koss and J. Sand, "CDIO projects in civil engineering study program at DTU," Proceedings of the 7th International CDIO Conference, Technical University of Denmark, Copenhagen, 2011 